UCRL- 89886

PREPRINT

CONF-8410186--3

PREDAMAGE THRESHOLD ELECTRON EMISSION

FROM INSULATOR AND SEMICONUUCTOR SURFACES

W. J. Siekhaus

J. H. Kinney

D. Milam

This paper was prepared for submittal to 16th Annual Symposium on Optical

Materials for High Power Lasers

Boulder, CO - October 15-17, 1984

February 5, 1985

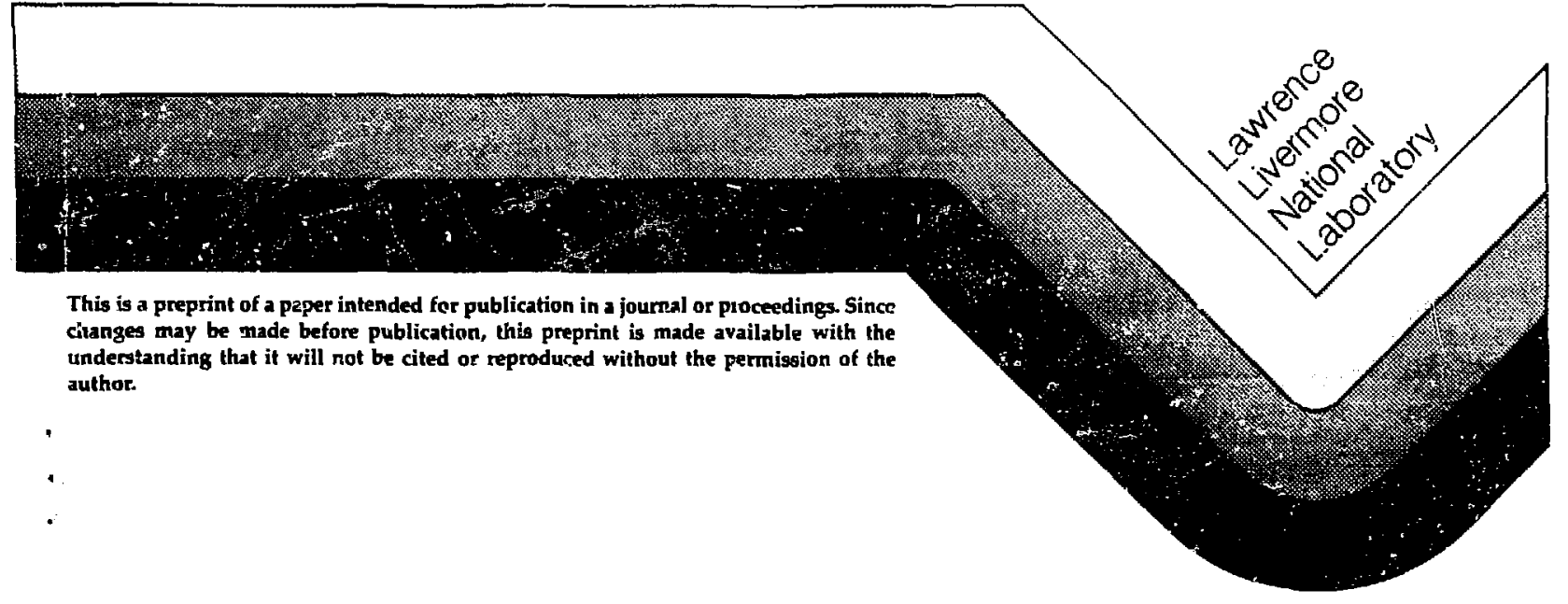




\title{
PREDAMAGE THRESHOLD ELECTRON EMISSION \\ FROM INSULATOR AND SEMICONDUCTOR SURFACES
}

\author{
W. J. Siekhaus and J. H. Kinney \\ Division of Chemistry and Materials Sciences
}

D. Mi 1 am

$Y$ Division

Lawrence Livermore National Laboratory

Livermore, California 94550

February 5, 1985

\section{DISCLAIMER}

This report was prepared as an account of work sponsored by an agency of the United States Government. Neither the Uniled States Government nor any agency theroof, nor any of their employees, makes any warranty, express or implied, or assumes any legal liability or responsibility for the accuracy, completeness, or usefulness of any information, apparatus, product, or process disclosed, or tepresents that its use would not infringe privately owned rights. Reference herein to any specific commercial product, process, or service by trade name, trademark, manufacturer, or atherwise does not necessarily constitute or imply its endorsement, recommendation, or favoring by the Unitad States Government or any agency thereof. The views and opinions of authors expressed berein do not aecessarily state or rillect those of the United States Goverament or any agency thereof. 
PREDAMAGE THRESHOLD ELECTRON EMISSION

FROM INSULATOR AND SEMICONDUCTOR SURFACES

\author{
W. J. Seikhaus, J. H. Kinney, D. Milam \\ Lawrence Livermore National Laboratory \\ Livermore, California 94550
}

\title{
ABSTRACT
}

Predamage electron emission shows a dependence on fluence, bandgap and wavelength consistent with multiphoton excitation across the bandgap and inconsistent with avalanche ionization and thermionic emission models.

The electron emission scaies with pulselength as $\tau^{-1 / 2}$.

\section{INTRODUCTION}

Optically transparent materials exposed to laser irradiation of sufficient intensity suffer irreversible damage, thereby limiting the performance of most high power laser systems. Tine damage threshold in the bulk depends on its impurity concentration. The threshold for optical surfaces is usualily lower, as much as an order of magnitude or more, and is highly dependent on surface preparation. The physical phenomena involved in damage are presently not well understood. [1]

*Work performed under the auspices of the U. S. Department of Energy by the Lawrence Livermore National Laboratory under contract number W-7405-ENG-48. 
Damage at bare surfaces appears to result from electron avalanche-ionization and subsequent absorption by the created plasma. One has to postulate that the electron 3 alanche fonization creates a conduction band electron density of $\mathrm{N}>10^{17} \mathrm{el} / \mathrm{cm}^{3}$ in the surface region for damage to occur. [2] Al yassini and Parks ${ }^{[3]}$ estimated from changes in the reflected intensity of a probe beam that $10^{18} \mathrm{el} / \mathrm{cm}^{3}$ are present in the conduction band at the surface when damage occurs.

In this study we measure the emission of these electrons from surfaces of insulators and semiconductors as a function of laser intensity, wavelength and pulse duration.

The long range objective is to use photoelectron emission as a tool to predict surface damage thresho?ds and to determi ne the effect of surface structures and surface composition on damage thresholds.

Laser induced charged particle emission from insulator surfaces has been studied before (see ref. 4 and references therein), but found to be irreproducible. It is our contention that the irreproducibility is a consequence of irreproducible surface conditions created by performing the experiments in vacua with pressures great than $10^{-6}$ torr.

\section{EXPERIMENTAL PROCEDURE}

We used equipment and techniques developed at LLML for rapid and relfable laser-damage threshold measurements. ${ }^{[5]}$ The laser has a wavelength of $1064 \mathrm{~nm}$ and a pulse-width variable from $1 \mathrm{~ns}$ to $40 \mathrm{~ns}$. Frequency doubling and 
tripling equipment has been used. Laser pulse energy is measured by calorimeters developed at LLNL. The peak fluence is measured in two ways: (1) A silicon-vidicon system ${ }^{[6]}$ electronically. records pulse intensity and computer analysis determined peak fluence within several minutes after exposure. (2) The pulse also exposes a photographic plate, which is later developed, densitometered and analyzed to obtain peak fluence. Agreement between these two measurements in now $\pm 10 \%$.

The target is held inside a insulated faraday cup suspended on a precision manipulator î̀ a UHV vacuum system (Figure 1). The openings in a Faraday cup are slits $1 / 2$ inch wide and 1 inch high. The beam diameters is ar proximately $3 \mathrm{~mm}$. The diameter of the inner Faraday cup is 4 inches. In the experiments reported here no voltage is applied between the target and the Faraday cage. The enitted charge is measured with a Digital Keithley Autoranging Coulombmeter (Model 616). During the laser pulse the fon pump and the ion gauge are switched off to reduce the background of charged particles in the chamber held at pressures lower than $10^{-7} \mathrm{~Pa}$ by a Helium Cryopump. An experiment begins by exposing the target to several laser pulses with a fluence $1 / 4$ to $1 / 2$ of the damage threshold until reproducible electron elnission is measured. These "surface cleaning" pulses are associated with measurable bursts in the pressure of the vacuum chamber, indicating that laser stimulated desorption of contaminants from the target surface occurs. Re-contamination of the surface thereafter is small since the 1 aser fires approximately every 3 minutes, and only a small fraction of a monolayer would readsorb from the vacuum environment at $10^{-7}$ Pa during 3 minutes. A1 1 
measurements are performed on the same precleaned spot unless the damage threshold is accidentally exceeciz. A new spot is then cleaned. The new spot yields the same results, within experimental errors. The data shown in the next section are usually from a number of different sites.

\section{RESULTS}

1.) Electron emission as a function of Laser Fluence (Pulse length = 1 ns). Figure 2 shows electron emission as a function of fluence for $\mathrm{ZnS}$ and $\mathrm{SiO}_{2}$ for hv $=1.16 \mathrm{eV}$. The slope of the best fit lines is indicated. Figure 3 gives electron emission as a function of laser fluence for hv $=$ $3.5 \mathrm{eV}$ for $\mathrm{W}, \mathrm{ZnS}, \mathrm{GeO}_{2}$ and $\mathrm{SiO}_{2}$. Table I summarized the observed functional dependence of electron emission as a function of fluence for two wavelengths and a number of different materials.

2.) Electron emission as a function of pulselength. Figures 4 and 5 depict the electron emission from CdTe as a function of laser fluence for $\mathrm{hu}=1.16 \mathrm{eV}$ at pulselenigths of $1 \mathrm{~ns}, 9 \mathrm{~ns}$ and $40 \mathrm{~ns}$. In Figure. 5 the fluences at different pulselengths are scaled according to (pulse length) ${ }^{1 / 2}$, e.g., the electron emission observed for fluence I is plotted at fluence $\mathrm{I} /(\text { pulse-length })^{1 / 2}$. Figure 6 documents for $\mathrm{hv}=1.16 \mathrm{eV}$ the electron emission as a function of fluence from $\mathrm{ZnS}$ for 1 ns and 20 ns pulselength. In Figure 7 we have plotted for $h \nu=1.16 \mathrm{eV}$ the electron emission from $\mathrm{NaCl}$ as a function of fluence for 1 ns and 40 ns pulselength. In Figure 8 the results for $40 \mathrm{~ns}$ pulselength have been plottad at a flux scaled by $40^{-1 / 2}$. 


\section{SUMMARY}

The results of laser induced electron emission from surfaces allow the following conclusions:

1) The electron emission shows a functioral variation with fluence up to the damage threshold consistent with a model that assumes that electron emission into the vacuum is controlled by multiphoton excitation across the bandgap (see table 1). The dependence on bandgap and wavelength are inconsistent with a model assuning themionic electron emission.

2) There is no evidence of an avalanche process as one approaches the threshold for optically visible damage.

3) The electron emission scales with pulselengths for materials with narrow and wide bandgaps as $\tau^{-1 / 2}$, when $\tau$ is the puiselength.

CONCLUSION

Pre-damage electron emission is a reproducible measure of the approach of a surface to the damage threshold. The spatial variation of electron emission will be used in the future to determine which local impuricies or local structural variations lead to damage. 


\section{REFERENCES}

[1] W. L. Smith, "Laser-Induced Breakdown in Optical Materials," Optical Engineering 17, 489 (1978), A. J. Glass, A. H. Guenther, Eds., NBS Special Publication 509.

[2] S. Brawer, "Phenomenological Theory of Laser Induced Damage in Insulators," Phys. Rev. B20, 3422, (1979).

[3] N. Alyassini and J. H. Parks, J. App1. Phys. 48, 629 (1977).

[4] V. P. Krutyakova and V. N. Smitnov, Sov. Phys. Tech. Phys. 24 (9) Sept. 1979.

[5] D. Milam, "Measurement and Identification of Laser Damage Thresholds in Thin Films, "Proceeding of the Society of Photo-Optical Instrumentation Engineers, Vol. 140, Optical Coatings II.

[6] W. L. Smith, A. J. DeGroot, and M. T. Weber, "Silicon Vidicon Systems for Measuring Laser Intensity Profiles," Appl. Opt. 17, 3938 (1978). 


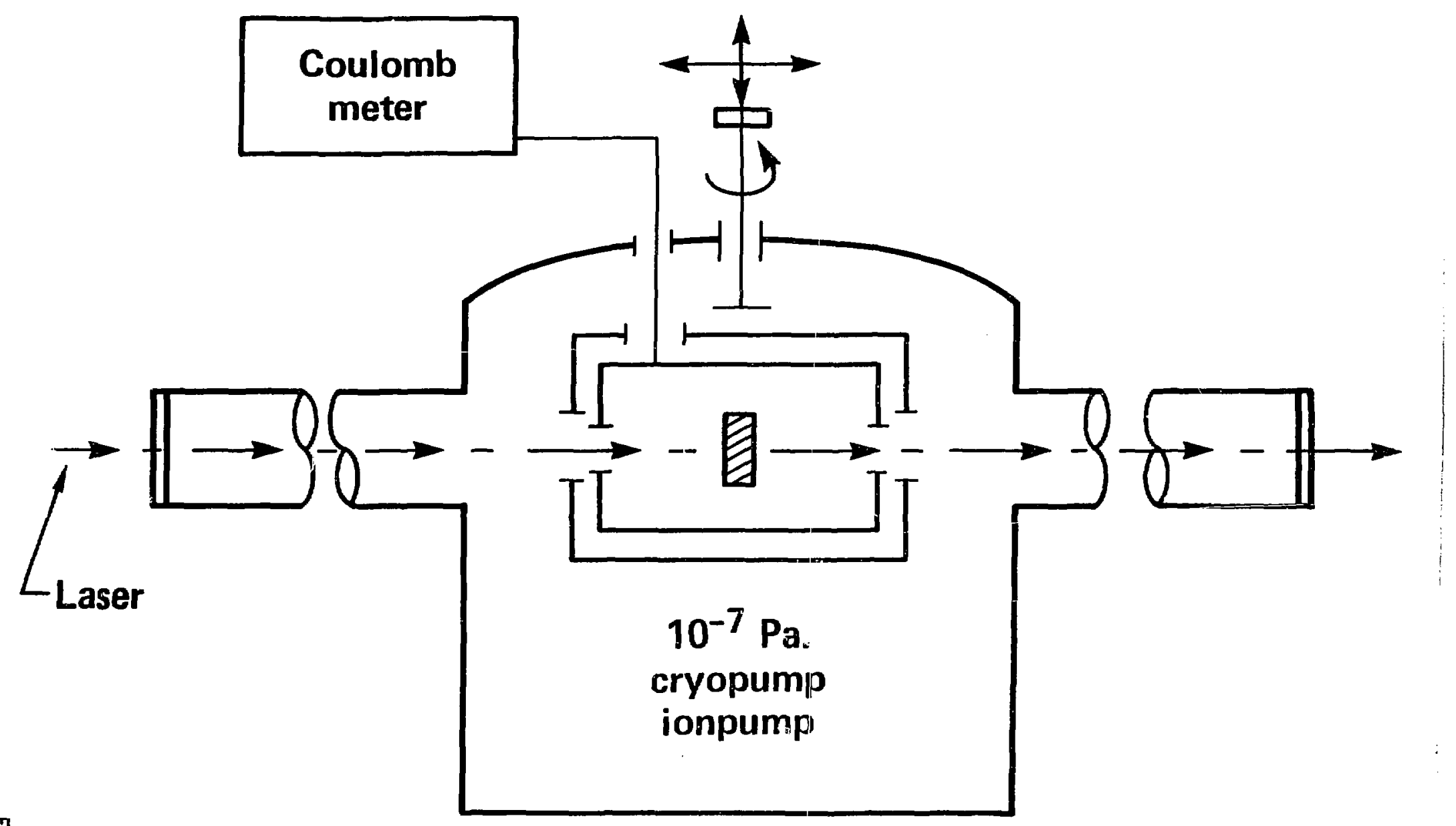




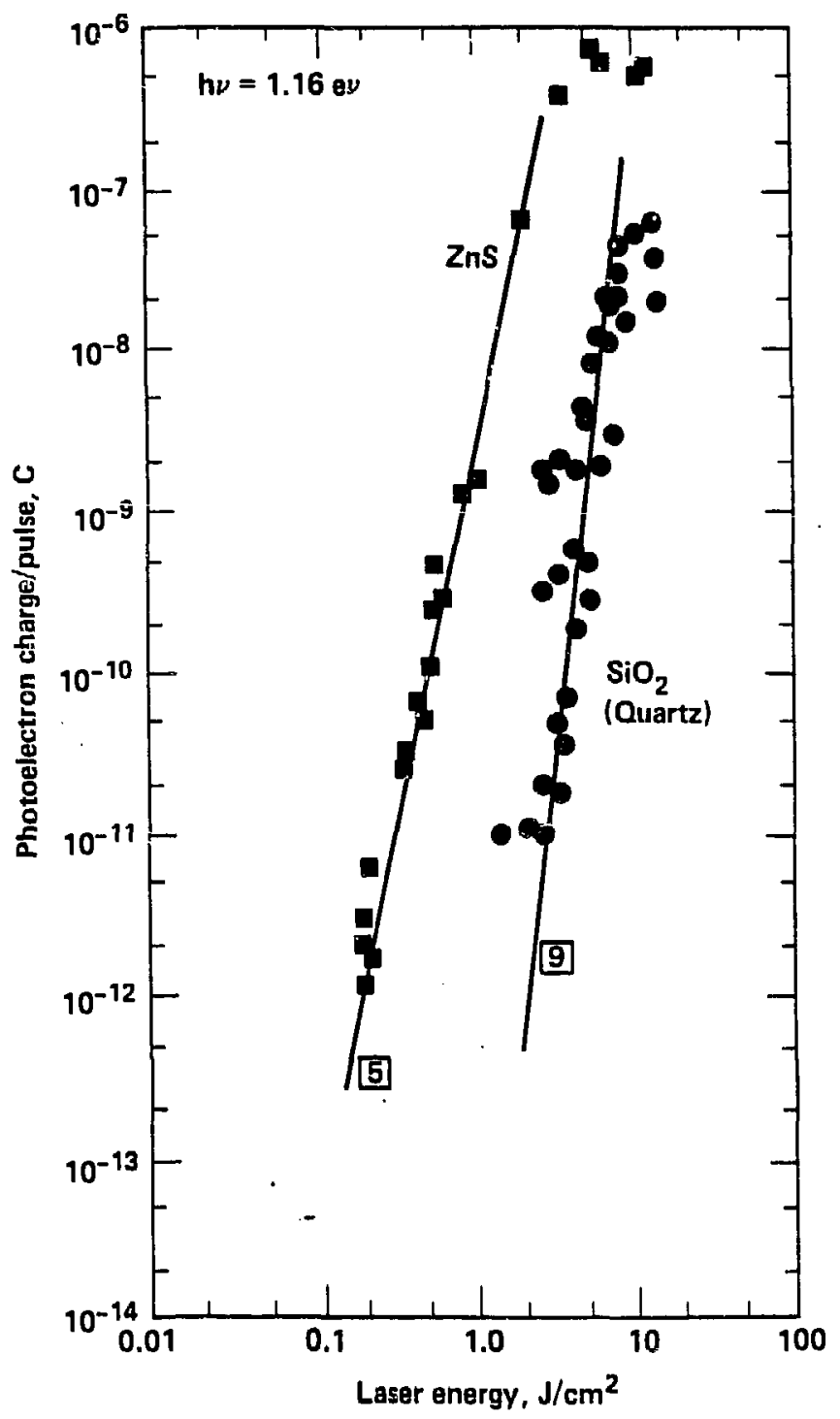

Fig. 2. Electron emission as a function of fluence. $h v=1.16 \mathrm{eV}$ 


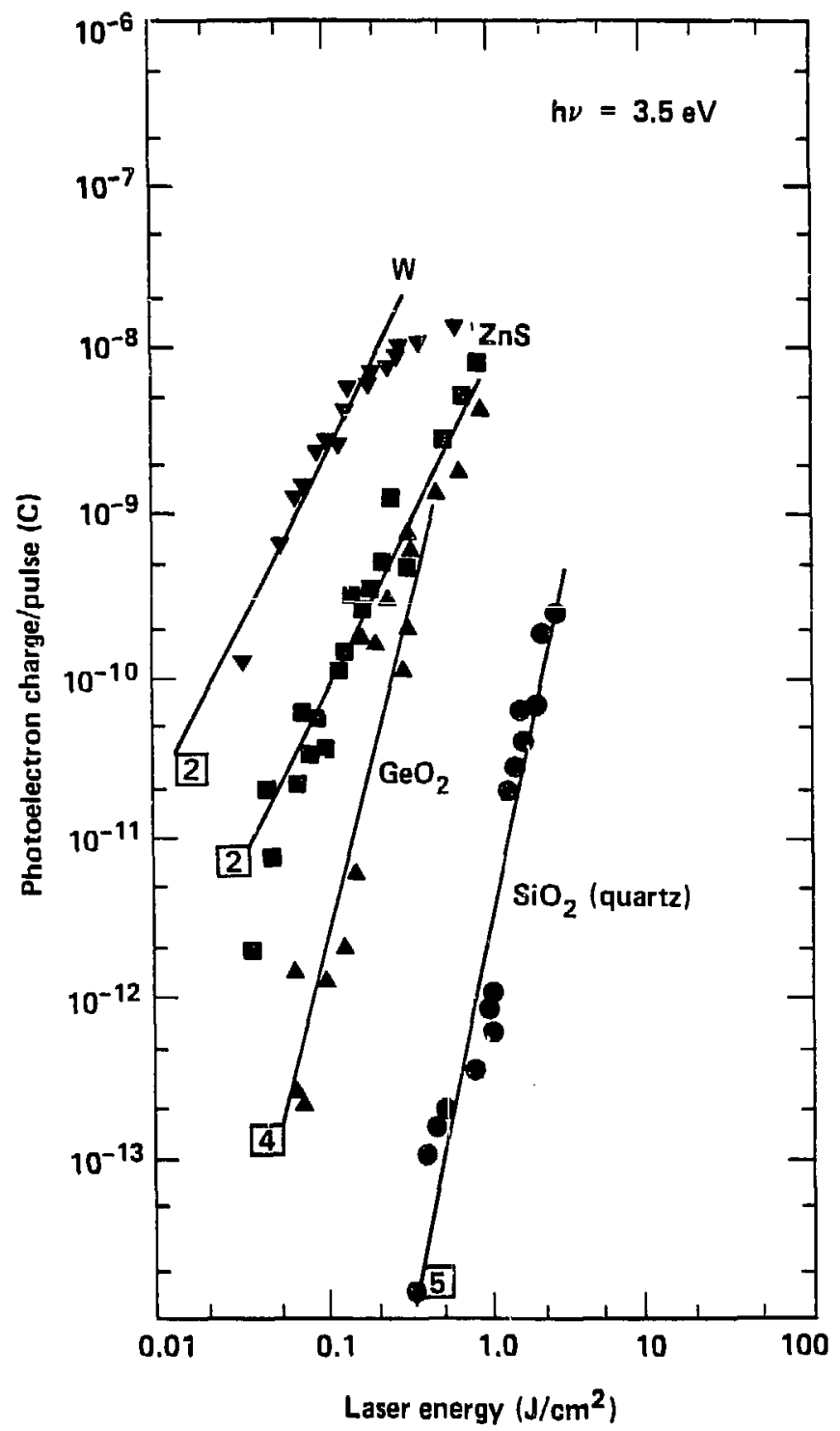

Fig. 3 Electron emission as a function of fluence. hv $=3.5 \mathrm{eV}$ 


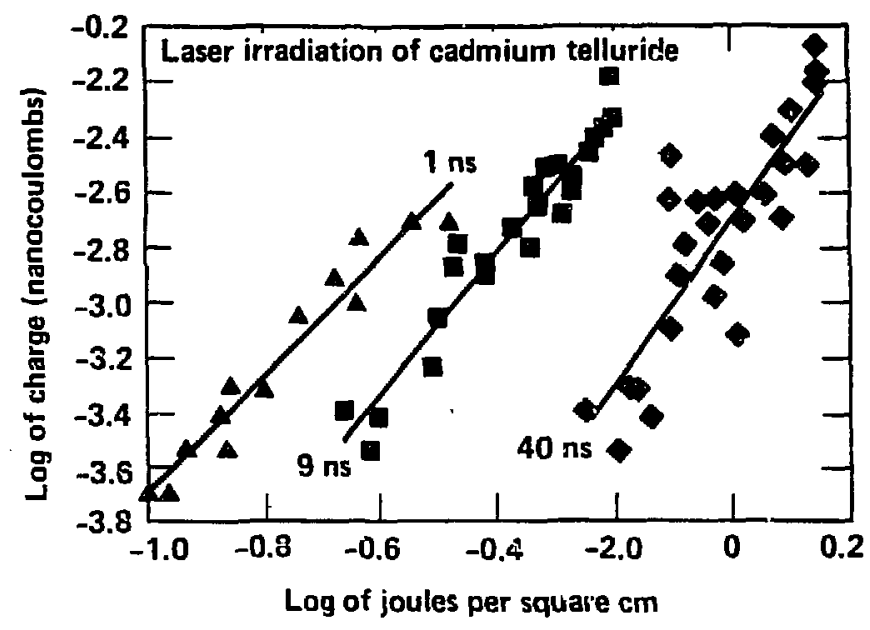

Fig. 4 Electron emission from CdTe as a function of fluence. Pulse length $1 \mathrm{~ns}, 9 \mathrm{~ns}$,

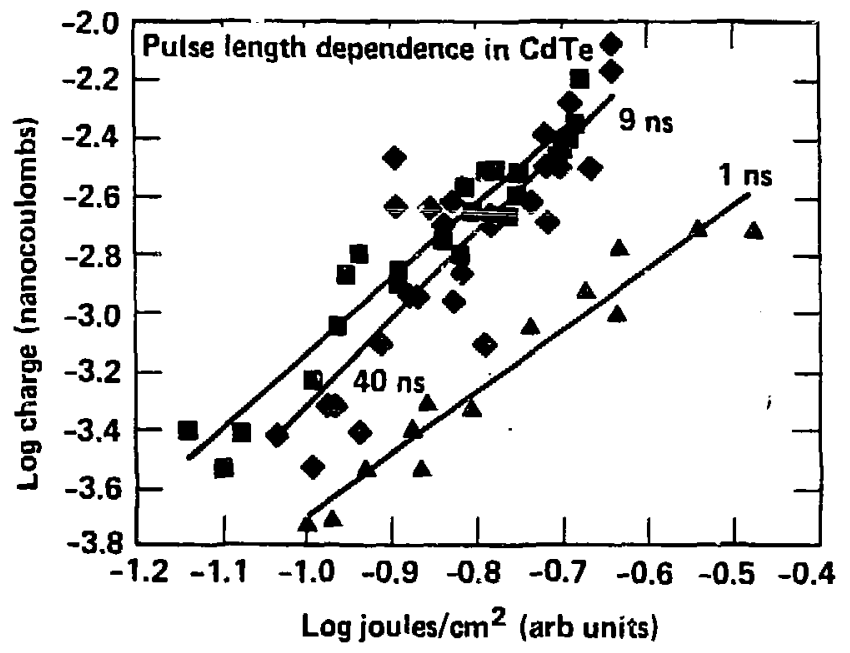

Fig. 5 Electron emission from CdTe as a function of fluence. Pulse length 1 ns, 9 ns, 40 ns. This abscissa s scaled by (pul se length)- $1 / 2$ for each pul se length. 


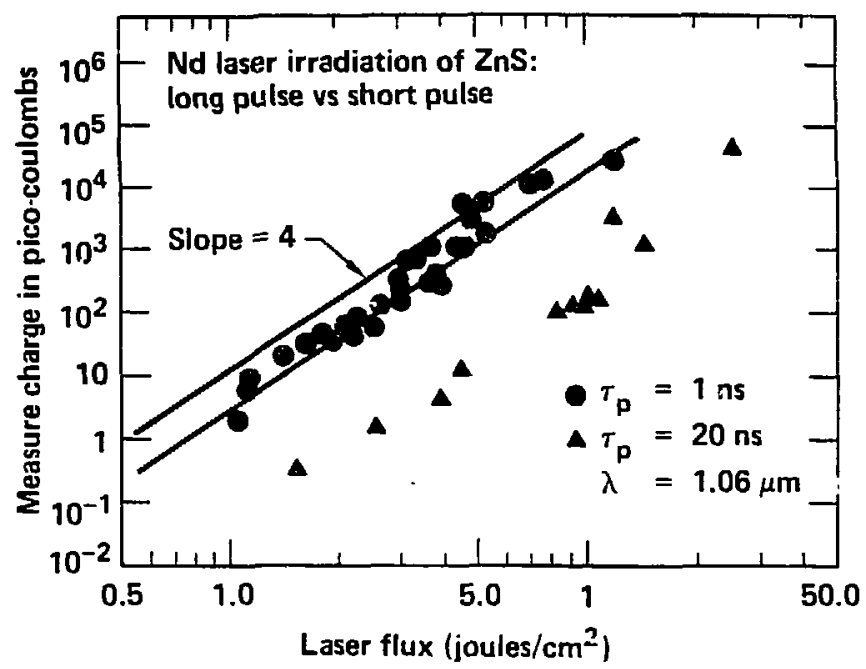

Fig. 6 Electron emission from ZnS as a function of fluence. Pulse length I ns and 40 ns.

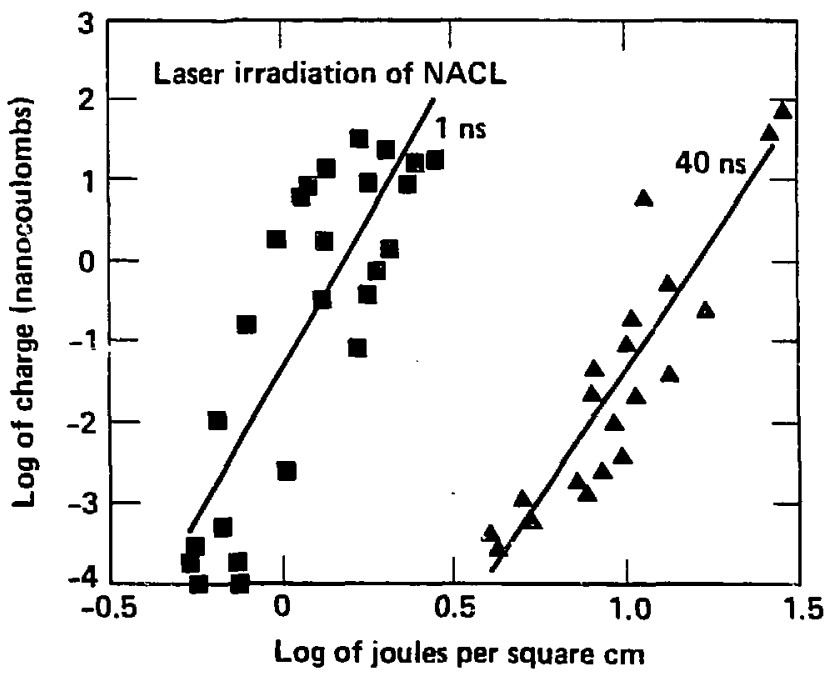

Fig. 7 Electron emission from $\mathrm{NaCl}$ as a function of fluence. Pulse length 1 ns and 40 ns. 


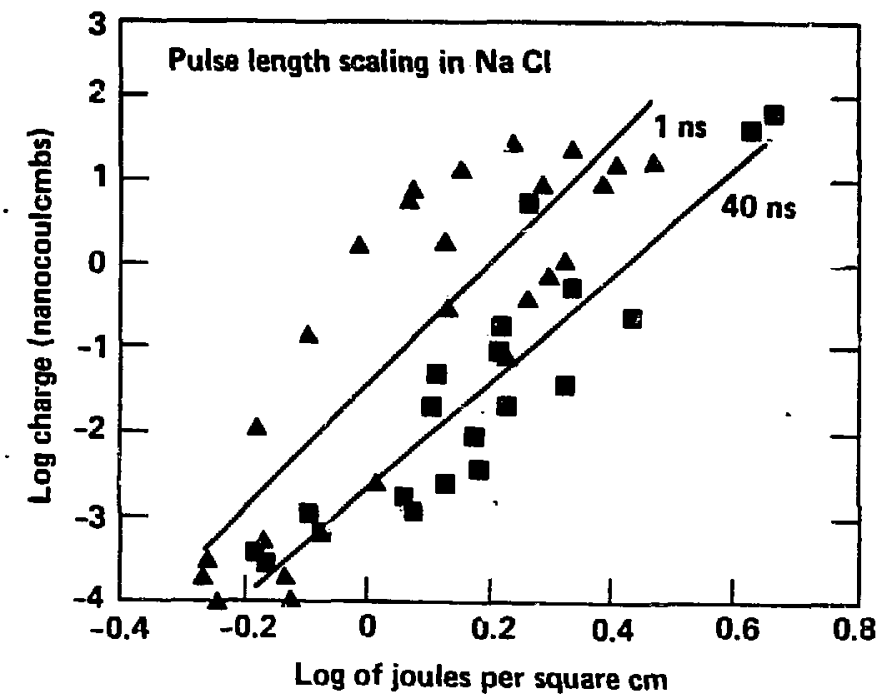

Fig. 8 Electron emission from $\mathrm{NaCl}$ as a function of fluence. Pulse length 1 ns and 40 ns. The abscissa is scaled by (pulse length) -172 for the 40 ns pulse length experiments.

Table 1

\begin{tabular}{|c|c|c|c|c|c|}
\hline Material & $E_{\text {gap }}(\mathrm{eV})$ & $E_{\text {work }}(\mathrm{eV})$ & $E_{\gamma}$ & $N_{\text {predicted }}^{*}$ & $N_{\text {observed }}^{*}$ \\
\hline $\mathrm{CdTe}$ & 1.5 & 6.0 & 1.16 & 2 & 2 \\
$\mathrm{NaCl}$ & 8.75 & 4.2 & 1.16 & 8 & $8-9$ \\
$\mathrm{SiO}_{2}$ & $8-8.4$ & 5.0 & 1.16 & 7.8 & 9 \\
& & & 3.5 & 3 & 5 \\
$\mathrm{ZnS}$ & 3.88 & 5.5 & 1.16 & 4 & 4.5 \\
& & & 3.5 & 2 & 2 \\
\hline \multicolumn{2}{|c|}{ *Predicted slope from a simple, multiphoton model: (E) $=\mathrm{Al}$} \\
\hline
\end{tabular}

